\title{
Attitude and perceptions towards COVID-19 among pregnant women in Singapore: A cross-sectional survey
}

ryan wai kheong lee ( $\nabla$ ryan.lee.wai.kheong@singhealth.com.sg )

Department of Maternal-Fetal Medicine, KK women and Children's Hospital loy see ling

Department of Reproductive Medicine, KK Women's and Children's Hospital yang liying

Duke-NUS Medical School

jerry kok yen chan

Department of Reproductive Medicine, KK Women's and Children's Hospital

Tan Lay Kok

Duke-NUS Medical School

\section{Research Article}

Keywords: Attitude, perceptions, COVID-19, pregnant, survey

Posted Date: September 3rd, 2020

DOl: https://doi.org/10.21203/rs.3.rs-67288/v1

License: (9) This work is licensed under a Creative Commons Attribution 4.0 International License. Read Full License 


\section{Abstract}

\section{Background}

COVID-19 may predispose pregnant women to higher risks of severe disease and poorer neonatal outcome. Psychological sequalae of this pandemic may pose a greater conundrum than its clinical aspects. It is currently unknown that how pregnant women cope with this global pandemic and its ramifications. The aims of the study are to understand the attitude and perceptions of non-infected pregnant women towards the COVID-19 outbreak in Singapore.

\section{Methods}

An online cross-sectional survey of COVID-19 awareness among pregnant women attending antenatal clinics in Singapore was conducted. An internet link was provided to complete an online electronic survey on Google platform using a quick response (QR) code on mobile devices. The online survey consists of 34 questions that were categorized into 4 main sections, namely 1) social demographics 2) attitude on safe distancing measures 3 ) precaution practices and 4) perceptions of COVID-19.

\section{$\underline{\text { Results }}$}

A total of 167 survey responses were obtained over eight weeks from April to June 2020. The majority of women were aged $\leq 35$ years $(76 \%, n=127)$, were of Chinese ethnicity $(55 \%, n=91)$, attained tertiary education $(62 \%, n=104)$ and were not working as frontline staff $(70 \%)$. Using multiple linear regression models, Malay ethnicity (vs. Chinese, $\beta 0.24 ; 95 \% \mathrm{Cl} 0.04,0.44$ ) was associated with higher frequency of practicing social distancing. Malay women $(\beta 0.48 ; 95 \% \mathrm{Cl} 0.16,0.80)$ and those who worked as frontline staff $(\beta 0.28 ; 95 \% \mathrm{Cl} 0.01,0.56)$ sanitized their hands at higher frequencies. Age of $\geq 36$ years (vs. $\leq 30$ years, $\beta 0.24 ; 95 \% \mathrm{Cl} 0.01,0.46$ ), Malay (vs. Chinese, $\beta 0.27 ; 95 \% \mathrm{Cl} 0.06,0.48$ ) and Indian ethnicity (vs. Chinese, $\beta 0.41 ; 95 \% \mathrm{Cl} 0.02,0.80$ ), and attendance at high-risk clinic (vs. general clinic, $\beta 0.20 ; 95 \% \mathrm{Cl}$ $0.01,0.39)$ were associated with higher frequency of staying-at-home.

\section{Conclusion}

It is important for clinicians to render appropriate counselling and focused clarification on the effect of COVID-19 among pregnant women for psychological support and mental wellbeing.

\section{Background}

Coronavirus disease (COVID-19) is an infectious disease caused by a newly discovered severe acute respiratory syndrome coronavirus (SARS-CoV-2) first identified in Wuhan City, China, in December 2019 [1]. On $11^{\text {th }}$ March 2020, the World Health Organization (WHO) declared the COVID-19 outbreak as a global pandemic with exponential spread worldwide [2]. As of 4 August 2020 , there are currently over 18 
million people globally affected by COVID-19 with over 700,000 deaths reported worldwide, and rising [3]. In Singapore, the total confirmed cases are over 53,000 with 27 deaths based on the Ministry of Health's $(\mathrm{MOH})$ report on 4 August 2020) [4].

The effects of SARS-CoV-2 in pregnancy had been based upon previous experience with SARS-CoV-1 and Middle East Respiratory Syndrome-related coronavirus (MERS) initially [5-6]. However, SARS-CoV-2 turns out to be far more infectious, albeit with lower mortality and similar morbidity to women of reproductive age [7]. The rapidly evolving pandemic over the past six months has given rise to multiple livingguidelines for the management of COVID-19 in pregnancy from a range of professional bodies such as the Royal College of Obstetricians \& Gynaecologists (RCOG), American College of Obstetricians and Gynaecologists (ACOG) and the Academy of Medicine in Singapore [8-10]. As our knowledge of COVID-19 increases, hospital recommendations on infection control, COVID-19 screening and isolation protocols change rapidly in accordance with the latest evidence. The physiological and immunological changes in pregnancy also make women more susceptible to severe illness from respiratory infections [11-12]. A recent Centre for Disease Control and Prevention (CDC) report demonstrated that pregnant women with COVID-19 are more likely to be hospitalised, admitted to the intensive care unit and receive mechanical ventilation albeit with similar risk of mortality compared to non-pregnant women [13].

Pregnancy itself poses logistical challenges and conundrums for obstetricians managing pregnant women with suspected or diagnosed with COVID-19. The RCOG suggests that the COVID-19 pandemic increases the risk of perinatal anxiety, depression, and domestic violence in pregnant women [8]. Hence, pregnant women deserve a more sensitive approach and mutual understanding during this global pandemic among clinicians and their partners. There are limited studies assessing the attitude and public perceptions towards the effect of COVID-19 among pregnant women. As the COVID-19 pandemic continues to intensify globally, it is timely that clinicians should better understand the mentality of pregnant women; render appropriate counselling and focused clarification for support during the antenatal, intra partum and post- partum period.

Social media and information access in Singapore are readily available via the internet. Hence, public awareness of COVID-19 using an online survey is realistic in both developing and developed countries with adequate resources for disseminating and receiving information. Herein, we reported the results from a rapid online cross-sectional survey related to COVID-19 among pregnant women attending antenatal clinics in Singapore.

The survey aimed to 1) establish the baseline attitudes, practices and perceptions of pregnant women towards COVID-19 and 2) correlate socio-demographics with women's precautionary practices.

\section{Methods}

We conducted an online cross-sectional survey for pregnant women attending antenatal clinics in two large tertiary-referral hospitals in Singapore from April to June 2020. Approval for the study including 
waiver of informed consent was obtained from the Singhealth Centralised Institutional Review Board (CIRB 2020/2307).

Pregnant women attending antenatal clinics were provided with an internet link to complete an online electronic survey on Google platform using a quick response (QR) code on any mobile device with internet access. The survey was anonymous and could be completed in about 10 minutes. The online electronic survey was created using CHERRIES (Checklist for Reporting Results of Internet E-Surveys) [14] and the questions were designed by a group of senior obstetricians.

The online survey consisted of 34 questions that were categorized into 4 main sections, namely 1) social demographics (Q1-Q10), 2) attitude on safe distancing measures (Q11-17), 3) precaution practices towards COVID-19 (Q18-21) and 4) perceptions of COVID-19 in the antepartum period (Q22-Q27), intrapartum care (Q28-Q30) and post-partum care. (Q31-Q34). (Appendix 1).

The survey was designed to capture general awareness of COVID-19 and perceived views on COVID-19 including social distancing measures, preferred mode of delivery, willingness to separate from their child at birth and avoiding breast feeding to minimize the risk of vertical neonatal transmission. We classified pregnant women attending the high-risk clinics based on obstetric indications by their clinicians whereas low risk pregnant women attended general clinics.

Responses to the questions were rated in different scales, 1) Yes, No, Not Sure, or 2) Not often, Occasionally, Often, Very often, or 3) Never, Rarely, Sometimes, Usually, Always. Respondents did not receive any incentive to complete the survey and standard of care was not affected if they did not participate in the online survey. Respondents had to provide a response to every question to complete the survey. The electronic data were compiled and saved on a secured website that was password protected to access the data with no identifiable patient information available.

Women's characteristics and distributions of their attitudes, practices and perceptions towards COVID-19 were presented in frequencies and percentages. Multiple linear regression analysis was performed to examine the main factors associated with women's precautionary practices among the six independent socio-demographic variables, including age ( $\leq 30,31-35, \geq 36$ years), ethnicity (Chinese, Malay, Indian, others), education (primary or secondary, post-secondary, tertiary), front-line jobs (no, yes), history of miscarriage (no, yes) and type of antenatal clinic (general , high risk). The scales of the dependent variables were treated in continuous form to increase the power of analysis. Data were presented as $\beta$ coefficients and $95 \%$ confidence interval (Cls). Statistical analysis was performed using the IBM SPSS Statistic Package, version 20.0 (IBM Corp., Armonk, N.Y., USA).

\section{Results}

A total of 167 survey responses were obtained over eight weeks from April to June 2020. The clinical characteristics and demographics are presented in Table 1. Among the included women, the majority of them were aged $\leq 35$ years $(76 \%, n=127)$, were of Chinese ethnicity $(55 \%, n=91)$, attained tertiary 
education $(62 \%, n=104)$ and were not working as frontline staff $(70 \%)$. In terms of obstetric history, most women conceived naturally $(90 \%, n=149)$, were primiparous $(51 \%, n=85)$ and at their third trimester of pregnancy $(44 \%, n=74)$, had no history of miscarriage $(80 \%, n=134)$ and were currently followed up in general clinics $(75 \%, n=125)$.

Table 2 and Table 3 shows the distribution of participants' attitude (Q11-17), precautionary practices (Q18-21) and perceptions ( Q22-34) towards COVID-19 in pregnancy. One hundred twenty-four women (74\%) were worried and very worried about being infected with COVID-19 in pregnancy (Q23). Seventyseven (46\%) women remained neutral if pregnant women infected with COVID-19 are more likely to miscarry or go into pre-term labour (Q27). Seventy-eight (47\%) women think that there is high risk of COVID-19 infection to their baby at the time of delivery if they were diagnosed with COVID-19 (Q25) and eighty-nine (53\%) women would choose having a caesarean section over a vaginal delivery if they were diagnosed with COVID-19 (Q30). After delivery, fifty-eight (35\%) women preferred to breast feed if they were diagnosed with COVID-19 (Q34). These questions did not show any association in relation to sociodemographic factors (data not shown).

Table 4 shows the associations of women's socio-demographics with precautionary practices towards COVID-19 based on multiple linear regression models. Malay (vs. Chinese, $\beta 0.24 ; 95 \% \mathrm{Cl} 0.04,0.44$ ) was associated with higher frequency of practicing social distancing (Q18). Age of $\geq 36$ years (vs. $\leq 30$ years, $0.24 ; 0.01,0.46$ ), Malay (vs. Chinese, $0.27 ; 0.06,0.48$ ) and Indian ethnicity (vs. Chinese, $0.41 ; 0.02,0.80$ ), and attendance to high-risk clinic (vs. general clinic, $0.20 ; 0.01,0.39$ ) were associated with higher frequency of staying-at-home behaviour (Q19); whereas front-line job (vs. non-front-liner, $-0.22 ;-0.40$, -0.04 ) and miscarriage experience (vs. no history of miscarriage, $-0.28 ;-0.49,-0.07$ ) were associated with lower frequency of home staying. Compared to women aged $\leq 30$ years, those aged $31-35$ years $(-0.33$; $-0.61,-0.05)$ and $\geq 36$ years $(-0.36 ;-0.69,-0.04)$ were less often to wear masks at home or in the public (Q20). In terms of hand hygiene practices, Malay women $(0.48 ; 0.16,0.80)$ and those who worked as frontline staff $(0.28 ; 0.01,0.56)$ sanitized their hands at higher frequencies (Q21).

\section{Discussion}

To the best of our knowledge, our study is hitherto the first study performed in a South East Asian population of pregnant women. Factors like race, religion, education background and employment status can influence women's attitude, practice and perception especially in an affluent country like Singapore. Our survey showed that Malay pregnant women are likely to practice safe distancing and sanitise their hands at a higher frequency compared to Chinese to minimise the spread of COVID-19. In addition, women attending high-risk clinics are more likely to stay at home compared to women attending general clinic.

Employed individuals who worked in front line services such as healthcare, hospitality have a lower tendency to stay home for social distancing, possibly driven by their more sociable or outgoing characteristics when compared to those do not work in front line. Conversely, our study also 
showed that employed individuals with front line jobs are more likely to practice hand hygiene compared to those who do not to reduce the risk of infection. In our study, women with history of miscarriage history had lower tendency to stay home for maintaining social distancing (Q19, $\beta$ : -0.22) suggesting that obstetric experience did not make women more cautious to practice social distancing to protect themselves. The same inverse associations were observed for Q18,Q20, Q21 with no significance.

There are currently limited cross-sectional studies addressing the attitude and perception of COVID-19 among pregnant women. Anikwe et al showed that majority of pregnant women in their third trimester in Nigeria demonstrated good attitude and preventative practices of COVID-19 [15] by practising hand washing, wearing masks, avoiding face touching and quarantine infected people as good practices towards the prevention of COVID-19 infection. These measures were performed without a 'lock-down' period unlike Singapore which implemented a colour-coded framework known as 'Disease Outbreak Response System Condition' (DORSCON) to guide the public on prevention and reducing the impact of COVID-19. There are four statuses namely Green, Yellow, Orange and Red of which Singapore is at orange currently which meant that the disease is severe but has not spread widely and is being contained [16]. The Singapore government implemented a 'circuit-breaker' in different phases' akin to lock-down period in other countries to curb the community spread of COVID-19 [17]. Safety measures implemented include staying mostly indoors and going outdoors only when necessary, practice social distancing at least one metre apart, wearing surgical masks in public places and adopting good hand sanitation practices to reduce the risk of community spread of COVID-19. Hence, pregnant women should be appropriately educated on preventative measures to reduce the severity of COVID-19 associated illness. Pregnant women should also avoid missing prenatal appointments if well and limit interactions with others to reduce the risk of transmission. Symptomatic women should be urged to be tested early for COVID-19 by nasopharyngeal or oropharyngeal swabs and practice self-isolation to reduce the risk of vertical transmission [18-19].

Yassa et al focused on Turkish pregnant women in attitude, concerns and knowledge towards COVID-19 from 30 weeks gestation onwards [20] where Turkey was one of the most affected countries then with over 20,000 cases and 425 deaths in April 2020 [21]. They showed that about $80 \%$ of women felt vulnerable towards the outbreak $45 \%$ of women were confused or doubtful about the mode of delivery and $50 \%$ wasn't sure if breast feeding was safe during the pandemic [20]. This is similar to our findings where $74 \%$ of women were worried about being infected with COVID-19; $53 \%$ of women would choose having a caesarean section over a vaginal delivery and only $35 \%$ of women will choose to breast feed if they were diagnosed with COVID-19. These views reflect the vulnerability of pregnant women despite differences in race or culture as pregnant women want the best outcome for themselves and minimize risk of vertical transmission to their baby.

In our study, $46 \%$ of pregnant women believed they are more likely to go into pre-term labour when infected with COVID-19. Di Mascio et al showed that $41.1 \%$ of pregnant women with COVID-19 had preterm birth before 37 weeks gestation, however that study did not distinguish between spontaneous and iatrogenic preterm birth [22]. A systemic review by A. Khalil et al also showed an $18.4 \%$ increase in 
iatrogenic preterm births before 37 weeks as these women were ill enough to require early caesarean deliveries [7]. This emphasizes the importance of imparting knowledge and educating women to to avoid unnecessary anxieties from non-evidenced based perceptions.

In our study, $46 \%$ of pregnant women also believed they are more likely to miscarry when infected with COVID-19. A systematic review by Zaigham et al did not report any adverse outcomes relating to perinatal outcomes [23]. Although results from the SARS epidemic did not suggest an increased risk of miscarriage or congenital anomalies associated with COVID-19 infection, more data is required before conclusions can be made on the risk of miscarriage [24].

In our study, almost three in four (74\%) of women were worried and very worried about being infected with COVID-19 in pregnancy. Durankus et al showed that pregnant women scored higher on the Edinburgh Postpartum Depression Scale (EPDS) when compared to the control group [25]. It is understandable for pregnant women to be anxious and this can be associated with a higher risk of depression [26]. This highlights the importance of providing psychosocial support especially in a vulnerable group of pregnant women. Clinicians should work in tandem with clinical psychologists and psychiatrists in a multi-disciplinary setting. The care of pregnant women should be tailored individually for the mental health of women and their babies.

Most cases of COVID-19 have evidence of human-to-human transmission where the virus appears to spread through respiratory, fomite or faecal methods [27-28]. There is also emerging opinion that the fetus may be exposed to be exposed during pregnancy. Perinatal infection may occur but its true incidence remains unknown. The likelihood of vertical transmission is low based on the United Kingdom Obstetric Surveillance System (UKOSS) interim study where six babies (2.5\%) had a positive nasopharyngeal swab for SARS-CoV-2 within 12 hours of birth in severely affected hospitalised women. [29]. Hence, the risk of vertical transmission in mild or asymptomatic patients is likely to be lower than that.

A case series published by Chen et al a tested amniotic fluid, cord blood, neonatal throat swabs and breast milk samples from COVID-19 infected mothers and all samples tested negative for the virus [30]. Conversely, two reported cases of possible vertical transmission showed evidence of immunoglobulin $\mathrm{M}$ (IgM) for SARS-CoV-2 in the neonatal serum [31-32]. Although direct evidence of viral positive reverse transcriptase-polymerase chain reaction (RT-PCR) were mostly negative in large majority of reported studies, the paucity of published data is limited with small cohort numbers, limited sensitivity and specificity of swab tests and rapid evolution of COVID-19 infection. [33-36]. Hence, more data is needed about the risk of vertical transmission before definitive conclusions can be made.

The mode of delivery should be discussed adequately with pregnant women taking into consideration their preferences and any obstetric indications. In our study, $53 \%$ of women would choose to have a caesarean section over a vaginal delivery if they were diagnosed with COVID-19. A. Khalil et al showed that nearly half of pregnant women infected with COVID-19 had caesarean deliveries [7]. As there is no convincing evidence of vertical transmission, vaginal delivery is not contraindicated in patients with 
COVID-19 [8,9]. Thus, Caesarean section is preferred over vaginal delivery in the face of maternal deterioration and fetal compromise where delivery is imminent. However, logistical issues can arise from the transfer of patients in hospital to labour ward or the availability of operating theatre to perform a caesarean section with negative pressure to minimize the risk of transmission. Hence, clinicians should counsel women on the appropriate mode of delivery as there is a lack of data and uncertainty surrounding the risk of perinatal transmission during vaginal deliveries.

In our study, only $35 \%$ of pregnant women will choose to breast feed if they were diagnosed with COVID19. There is also limited data to guide the postnatal management of babies of mothers who tested positive for COVID-19 in the third trimester of pregnancy. Currently, possibility of infection from breast milk remain uncertain although there is recent evidence to suggest a small risk of transmission through breast feeding [37-39]. As breast feeding requires close contact, direct breast feeding may be of concern in infected mothers. Hence, infected mothers should be advised to wear surgical masks, cleaning their breast before expression via breast pumps to bottle feed their neonates to reduce the risk of neonatal transmission. Precautionary separation of mother and child is debatable and cause loss of physical bonding and emotional attachment which have a negative psychological impact in infected women.

We chose to perform an online survey as this is a rapid and convenient mode of administration. Furthermore, we used CHERRIES (Checklist for Reporting Results of Internet E-Surveys) to ensure the quality of our web-based survey [14]. Limitations of our study include small sample size and lack of internal consistency of questions without validation. Despite our small sample size, the data collected likely representative of our local population as the two large public hospitals make up more than half of the obstetric load in Singapore. In addition, our findings may be influenced by possible selection bias because participants needed a mobile device with applications to scan the QR code to access the survey.

Ever-since the WHO declared COVID-19 a global pandemic, the world has seen an exponential number of rising cases and unprecedented death rates. Until a vaccine is found, herculean efforts rests on containing community spread of COVID-19 through means like testing for suspected cases, practising social distancing and maintaining good personal hygiene [40-42].

\section{Conclusion}

As much of COVID-19 remains hitherto unknown, current opinions regarding management of COVID-19 positive women may change with input of new knowledge. The physical burden of pregnancy makes it psychologically and emotional challenging in vulnerable pregnant women. Knowledge gained from our cross-sectional online survey can better guide clinicians to communicate better with pregnant women. Our study highlights the importance for clinicians to render appropriate counselling and focused clarification on the effect of COVID-19 among pregnant women for psychological support and mental wellbeing.

\section{Abbreviations}


ACOG: $\quad$ American College of Obstetricians and Gynaecologists

CDC: $\quad$ Centre for Disease Control and Prevention

CIRB: $\quad$ Centralised Institutional Review Board

CHERRIES: Checklist for Reporting Results of Internet E-Surveys

COVID-19: Coronavirus disease (COVID-19)

DORSCON: Disease Outbreak Response System Condition

EPDS: $\quad$ Edinburgh Postpartum Depression Scale

MOH: $\quad$ Ministry of Health

MERS: Middle East Respiratory Syndrome-related coronavirus

UKOSS: United Kingdom Obstetric Surveillance System

QR: $\quad$ Quick response

RCOG: $\quad$ Royal College of Obstetricians \& Gynaecologists

RT-PCR: Reverse transcriptase polymerase chain reaction

SARS-COV-2: Severe acute respiratory syndrome coronavirus

WHO: $\quad$ World Health Organization

\section{References}

1. Zhou F., Yu T., Du R., Fan G., Liu Y., Liu Z. Clinical course and risk factors for mortality of adult inpatients with COVID-19 in Wuhan, China: a retrospective cohort study. 2020 Mar 11 doi: 10.1016/S0140-6736(20)30566-3. pii: S0140-6736(20)30566-3

2. World Health Organisation. Coronavirus disease (COVID-2019) situation reports 2020 [Available from: https://www.who.int/emergencies/diseases/novel-coronavirus-2019/situation-reports accessed 01 July 2020

3. World Health Organisation. Coronavirus disease (COVID-2019) situation reports 2020 [Available from: https://www.who.int/emergencies/diseases/novel-coronavirus-2019 accessed 4 August 2020

4. Ministry of Health Singapore. Updates on COVID-19 ( coronavirus disease 2019 local situation). [Available from: https://www.moh.gov.sg/covid-19/ accessed 4 August 2020

5. Alfaraj, S. H., Al-Tawfiq, J. A., \& Memish, Z. A. (2019). Middle East Respiratory Syndrome Coronavirus (MERS-CoV) infection during pregnancy: Report of two cases \& review of the literature. Journal of 
Microbiology, Immunology and Infection, 52(3). https://doi.org/10.1016/j.jmii.2018.04.005

6. Wong SF, Chow KM, Leung TN et al, Tan PY. Pregnancy and perinatal outcomes of women with severe acute respiratory syndrome.AM J Obstet Gyecol 2004;191:292-297

7. Khalil et al., SARS-CoV-2 infection in pregnancy: A systematic review and meta-analysis of clinical features and pregnancy outcomes, EClinicalMedicine (2020), https://doi.org/10.1016/j.eclinm.2020.100446

8. Royal College of Obstetricians \& Gynaecologists. Coronovirus (COVID-19) Infection in Pregnancy Information for Healthcare Professionals. Version 11 July 24, 2020. ) [Available from: https://www.rcog.org.uk/globalassets/documents/guidelines/2020-07-24-coronavirus-covid-19infection-in-pregnancy.pdf accessed 2 August 2020

9. Coronavirus COVID-19, a practice advisory. [Available from https://www.acog.org/clinical/clinicalguidance/practice-advisory/articles/2020/03/novel-coronavirus-2019 accessed 4 August 2020

10. Academy of Medicine Singapore. Committee Opinion. [Available from : https://www.ams.edu.sg/viewpdf.aspx?file=media\%5C5443_fi_921.pdf\&ofile= (Committee+Opinion)+Management+of+Pregnancy+and+Birth+in+Women+with+Covid-19+April+ (20200420).pdf accessed 15 July 2020

11. Ramsey PS, Ramin KD. Pneumonia in pregnancy. Obstet Gynecol Clin North Am 2001;28:553-69. 10.1016/S0889-8545(05)70217-5

12. Rasmussen SA, Kissin DM, Yeung LF, et al.; Pandemic Influenza and Pregnancy Working Group. Preparing for influenza after 2009 H1N1: special considerations for pregnant women and newborns.Am J Obstet Gynecol 2011;204(Suppl 1):S13-20. 10.1016/j.ajog.2011.01.048

13. Ellington S, Strid P, Tong VT, et al. Characteristics of Women of Reproductive Age with LaboratoryConfirmed SARS-CoV-2 Infection by Pregnancy Status - United States, January 22-June 7, 2020. MMWR Morb Mortal Wkly Rep. 2020;69(25):769-775. Published 2020 Jun 26. doi:10.15585/mmwr.mm6925a1

14. Eysenbach G. Improving the quality of Web surveys: the Checklist for Reporting Results of Internet ESurveys (CHERRIES). J Med Internet Res. 2004 Sep 29;6(3):e34. doi: 10.2196/jmir.6.3.e34. Erratum in: doi:10.2196/jmir.2042.

15. Anikwe CC, Ogah CO, Anikwe IH, Okorochukwu BC, Ikeoha CC. Coronavirus disease 2019: Knowledge, attitude, and practice of pregnant women in a tertiary hospital in Abakaliki, southeast Nigeria [published online ahead of print, 2020 Jul 1]. Int J Gynaecol Obstet. 2020;10.1002/ijgo.13293. doi:10.1002/ijgo.13293

16. Ministry of Health Singapore. What do the different dorscon levels mean. [Available from:https://www.gov.sg/article/what-do-the-different-dorscon-levels-mean accessed 30 July 2020

17. Ministry of Health Singapor [Available from : https://www.moh.gov.sg/newshighlights/details/circuit-breaker-to-minimise-further-spread-of-covid-19 accessed 30 July 2020 
18. Rothan HA, Byrareddy SN. The epidemiology and pathogenesis of coronavirus disease (COVID-19) outbreak. J Autoimmun. 2020;109:102433. doi:10.1016/j.jaut.2020.102433

19. Struyf T, Deeks JJ, Dinnes J, et al. Signs and symptoms to determine if a patient presenting in primary care or hospital outpatient settings has COVID-19 disease. Cochrane Database Syst Rev. 2020;7:CD013665. Published 2020 Jul 7. doi:10.1002/14651858.CD013665

20. Murat Yassa, Pinar Birol, Cihangir et al, Niyazi Tug. Near-term pregnant women's attitude toward, concern about and knowledge of the COVID-19 pandemic, The Journal of Maternal-Fetal \& Neonatal Medicine (2020) . DOI: 1080/14767058.2020.1763947

21. Republic of Turkey, Ministry of Health. [Available from https://covid19.saglik.gov.tr/ accessed 2 August 2020

22. Di Mascio D, Khalil A, Saccone G, Rizzo G, Buca D, Liberati M, Vecchiet J, Nappi L, Scambia G, Berghella V, D'Antonio F. Outcome of Coronavirus spectrum infections (SARS, MERS, COVID 1 -19) during pregnancy: a systematic review and meta-analysis. Am J Obstet Gynecol MFM. 2020 Mar 25;2(2):100107. doi: 10.1016/j.ajogmf.2020.100107.

23. Zaigham M, Andersson O. Maternal and perinatal outcomes with COVID-19: a systematic review of 108 pregnancies. Acta Obstet Gynecol Scand. 2020. DOI: 10.1111/aogs.13867.

24. Shek CC, Ng PC, Fung GP, Cheng FW, Chan PK, Peiris MJ, et al. Infants born to mothers with severe acute respiratory syndrome. Pediatrics 2003 Oct;112(4):e254.

25. Durankuş F , Aksu E. Effects of the COVID-19 pandemic on anxiety and depressive symptoms in pregnant women: a preliminary study, The Journal of Maternal-Fetal \& Neonatal Medicine (2020). DOI: 1080/14767058.2020.1763946

26. Thapa SB, Mainali A, Schwank SE, Acharya G. Maternal mental health in the time of the COVID-19 pandemic. Acta Obstet Gynecol Scand. 2020;99(7):817-818. doi:10.1111/aogs.13894

27. Wang W, Xu Y, Gao R, et al. Detection of SARS-CoV-2 in different types of clinical specimens. JAMA. 2020. DOI:10.1001/jama.2020.3786.

28. Ong SW, Tan YK, Chia PY, Lee TH, Ng OT, Wong MS, et al. Air, surface environmental, and personal protective equipment contamination by severe acute respiratory syndrome coronavirus 2 (SARS-CoV2) from a symptomatic patient. JAMA. 2020 Mar 4.

29. Knight M, Bunch K, Vousden N, et al. Characteristics and outcomes of pregnant women admitted to hospital with confirmed SARS-CoV-2 infection in UK: national population based cohort study. BMJ 2020;369:m2107. doi: 10.1136/bmj.m2107

30. Chen $\mathrm{H}$ et al. Clinical characteristics and intrauterine vertical transmission potential of COVID19 infection in nine pregnant women: a retrospective review of medical records. Lancet 2020. https://doi.org/10.1016/S0140-6736(20)30360-3.

31. Dong L, Tian J, He S, et al. Possible Vertical Transmission of SARS-CoV-2 From an Infected Mother to Her Newborn [published online ahead of print, 2020 Mar 26]. JAMA. 2020;323(18):1846-1848. 
doi:10.1001/jama.2020.4621

32. Zeng L, Xia S, Yuan W, et al. Neonatal Early-Onset Infection With SARS-CoV-2 in 33 Neonates Born to Mothers With COVID-19 in Wuhan, China [published online ahead of print, 2020 Mar 26]. JAMA Pediatr. 2020;174(7):722-725. doi:10.1001/jamapediatrics.2020.0878

33. Huntley BJF, Huntley ES, Di Mascio D, Chen T, Berghella V, Chauhan SP. Rates of Maternal and Perinatal Mortality and Vertical Transmission in Pregnancies Complicated by Severe Acute Respiratory Syndrome Coronavirus 2 (SARS-Co-V-2) Infection: A Systematic Review [published online ahead of print, 2020 Jun 9]. Obstet Gynecol. 2020;10.1097/. doi:10.1097/AOG.0000000000004010

34. Juan J, Gil MM, Rong Z, Zhang Y, Yang H, Poon LC. Effect of coronavirus disease 2019 (COVID-19) on maternal, perinatal and neonatal outcome: systematic review. Ultrasound Obstet Gynecol. 2020;56(1):15-27. doi:10.1002/uog.22088

35. Ferrazzi E, Frigerio L, Savasi V, et al. Vaginal delivery in SARS-CoV-2-infected pregnant women in Northern Italy: a retrospective analysis [published online ahead of print, 2020 Apr 27]. BJOG. 2020;10.1111/1471-0528.16278. doi:10.1111/1471-0528.16278

36. Vivanti AJ, Vauloup-Fellous C, Prevot S, et al. Transplacental transmission of SARS-CoV-2 infection. Nat Commun 2020;11(1):3572. doi: 10.1038/s41467-020-17436-6 59

37. Wu Y, Liu C, Dong L, et al. Coronavirus disease 2019 among pregnant Chinese women: case series data on the safety of vaginal birth and breastfeeding [published online ahead of print, 2020 May 5]. BJOG. 2020;10.1111/1471-0528.16276. doi:10.1111/1471-0528.16276

38. Tam PCK, Ly KM, Kernich ML, et al. Detectable severe acute respiratory syndrome coronavirus 2 (SARS-CoV-2) in human breast milk of a mildly symptomatic patient with coronavirus disease 2019 (COVID-19) [published online ahead of print, 2020 May 30]. Clin Infect Dis. 2020;ciaa673. doi:10.1093/cid/ciaa673

39. Groß R, Conzelmann C, Müller JA, et al. Detection of SARS-CoV-2 in human breastmilk. Lancet. 2020;395(10239):1757-1758. doi:10.1016/S0140-6736(20)31181-8

40. Dashraath P, Wong JLJ, Lim MXK, Lim LM, Li S, Biswas A, Choolani M, Mattar C, Su LL. Coronavirus disease 2019 (COVID-19) pandemic and pregnancy. Am J Obstet Gynecol. 2020 Jun;222(6):521-531. doi: 10.1016/j.ajog.2020.03.021. Epub 2020 Mar 23.

41. Maclntyre CR, Wang Q. Physical distancing, face masks, and eye protection for prevention of COVID19 [published correction appears in Lancet. 2020 Jun 5;:]. Lancet. 2020;395(10242):1950-1951. doi:10.1016/S0140-6736(20)31183-1

42. Lewnard JA, Lo NC. Scientific and ethical basis for social-distancing interventions against COVID19. Lancet Infect Dis. 2020;20(6):631-633. doi:10.1016/S1473-3099(20)30190-0

\section{Tables}


Table 1 Characteristics of participants $(n=167)$

\begin{tabular}{|c|c|}
\hline Demographics & $\mathrm{n}(\%)$ \\
\hline \multicolumn{2}{|l|}{ Age } \\
\hline$\leq 30$ years & $56(33.5)$ \\
\hline 31-35 years & $71(42.5)$ \\
\hline$\geq 36$ years & $40(24.0)$ \\
\hline \multicolumn{2}{|l|}{ Ethnicity } \\
\hline Chinese & $91(54.5)$ \\
\hline Malay & $50(29.9)$ \\
\hline Indian & $8(4.8)$ \\
\hline Others & $18(10.8)$ \\
\hline \multicolumn{2}{|l|}{ Religion } \\
\hline Buddhist & $34(20.4)$ \\
\hline Christian & $28(16.8)$ \\
\hline Islam & $59(35.3)$ \\
\hline Others & $46(27.5)$ \\
\hline \multicolumn{2}{|l|}{ Education } \\
\hline Primary/ secondary & $16(9.6)$ \\
\hline Post-secondary & $47(28.1)$ \\
\hline Tertiary & $104(62.3)$ \\
\hline \multicolumn{2}{|l|}{ Frontline job } \\
\hline No & $116(69.5)$ \\
\hline Yes & $51(30.5)$ \\
\hline \multicolumn{2}{|l|}{ Type of conception } \\
\hline Natural & $149(89.8)$ \\
\hline IVF/IUI & $17(10.2)$ \\
\hline \multicolumn{2}{|l|}{ Trimester } \\
\hline First $<13$ weeks' gestation & $30(18.0)$ \\
\hline Second 13-26 weeks' gestation & $63(37.7)$ \\
\hline Third 27-40 weeks' gestation & $74(44.3)$ \\
\hline \multicolumn{2}{|l|}{ Number of living children } \\
\hline 0 & $85(50.9)$ \\
\hline 1 & $55(32.9)$ \\
\hline$\geq 2$ & $27(16.2)$ \\
\hline \multicolumn{2}{|l|}{ History of miscarriage } \\
\hline No & $134(80.2)$ \\
\hline Yes & $33(19.8)$ \\
\hline \multicolumn{2}{|l|}{ Type of clinic } \\
\hline General & $125(74.9)$ \\
\hline High-risk & $42(25.1)$ \\
\hline
\end{tabular}

Table 2 Distribution of participants attitude (Q11-17) and precautions (Q18-21) during towards COVID-19 


\begin{tabular}{|l|c|c|c|c|c|}
\hline Attitude & Not often & Occasionally & Often & Very often & \\
\hline & $\mathrm{n}(\%)$ & $\mathrm{n}(\%)$ & $\mathrm{n}(\%)$ & $\mathrm{n}(\%)$ & $\mathrm{n}(\%)$ \\
\hline & $1(0.6)$ & $16(9.6)$ & $59(35.5)$ & $90(54.2)$ & \\
\hline & & & & & \\
\hline & No & Not sure & Yes & & \\
\hline Q13 & $159(96.4)$ & 0 & $6(3.6)$ & & \\
\hline Q14 & $164(98.2)$ & $3(1.8)$ & 0 & & \\
\hline Q15 & $161(96.4)$ & 0 & $6(3.6)$ & & \\
\hline Q17 & $145(86.8)$ & 0 & $22(13.2)$ & & \\
\hline & $159(95.2)$ & 0 & $8(4.8)$ & & \\
\hline & & & & & \\
\hline Q16 & Not important & Not so important & Neutral & Somewhat important & \\
\hline & $1(0.6)$ & $3(1.8)$ & $13(7.8)$ & $24(14.4)$ & \\
\hline Precautions & & & & & \\
\hline & Never & Rarely & Sometimes & Usually & Always \\
\hline & $\mathrm{n}(\%)$ & $\mathrm{n}(\%)$ & $\mathrm{n}(\%)$ & $\mathrm{n}(\%)$ & $\mathrm{n}(\%)$ \\
\hline Q18 & $1(0.6)$ & 0 & $2(1.2)$ & $28(16.9)$ & $135(81.3)$ \\
\hline Q19 & 0 & 0 & $8(4.8)$ & $45(26.9)$ & $114(68.3)$ \\
\hline Q20 & $124(74.3)$ & $33(19.8)$ & $6(3.6)$ & & $4(2.4)$ \\
\hline Q21 & 0 & $5(3.0)$ & $26(15.6)$ & $52(31.1)$ & $84(50.3)$ \\
\hline
\end{tabular}

Table 3 Distribution of participants' perceptions (Q22-34) towards COVID-19

\begin{tabular}{|l|c|c|c|c|c|}
\hline Antepartum & Not often & Occasionally & Often & Very often & \\
\hline & $\mathrm{n}(\%)$ & $\mathrm{n}(\%)$ & $\mathrm{n}(\%)$ & $\mathrm{n}(\%)$ & $\mathrm{n}(\%)$ \\
\hline & $31(18.6)$ & $51(30.5)$ & $85(50.9)$ & $0(0)$ & \\
\hline & & & & & \\
\hline & Not worries & Not sure & Neutral & Worried & Very worried \\
\hline & $4(2.4)$ & $1(0.6)$ & $38(22.8)$ & $74(44.3)$ & $50(29.9)$ \\
\hline & & & & & \\
\hline & Low & Medium & High & Unsure & \\
\hline Q25 & $23(13.8)$ & $35(21.0)$ & $61(36.5)$ & $48(28.7)$ & \\
\hline Q26 & $11(6.6)$ & $36(21.6)$ & $78(46.7)$ & $42(25.1)$ & \\
\hline & $6(3.6)$ & $29(17.4)$ & $90(53.9)$ & $41(24.6)$ & \\
\hline & & & & & \\
\hline Q27 & Very unlikely & Unlikely & Neutral & Likely & Very likely \\
\hline & $5(3.0)$ & $30(18.0)$ & $77(46.1)$ & $41(24.6)$ & 14 (8.4) \\
\hline & & & & & \\
\hline Intrapartum & & Not sure & Yes & & \\
\hline Q28 & $20(12.0)$ & $52(31.1)$ & $95(56.9)$ & & \\
\hline Q29 & $35(21.0)$ & $59(35.3)$ & $73(43.7)$ & & \\
\hline Q30 & $21(12.6)$ & $57(34.1)$ & $89(53.3)$ & & \\
\hline Postpartum & & & & & \\
\hline Q31 & $96(57.5)$ & $33(19.8)$ & $38(22.8)$ & & \\
\hline Q32 & $22(13.2)$ & $33(19.8)$ & $112(67.1)$ & & \\
\hline Q33 & $7(4.2)$ & $4(2.4)$ & $156(93.4)$ & & \\
\hline Q34 & $66(39.8)$ & $42(25.3)$ & $58(34.9)$ & & \\
\hline
\end{tabular}


Table 4 Characteristics associated with precaution practices towards COVID-19

\begin{tabular}{|c|c|c|c|c|}
\hline Demographics & Q18 & Q19 & Q20 & Q21 \\
\hline Questions & $\begin{array}{l}\text { How often was } \\
\text { social distancing } \\
\text { practiced }\end{array}$ & $\begin{array}{l}\text { How often } \\
\text { did they } \\
\text { stay home }\end{array}$ & $\begin{array}{c}\text { How often was a } \\
\text { mask worn at } \\
\text { home/outside }\end{array}$ & $\begin{array}{c}\text { How often was } \\
\text { hand hygiene } \\
\text { practiced }\end{array}$ \\
\hline & $\beta(95 \%$ CI $)$ & $\beta(95 \% \mathrm{CI})$ & $\beta(95 \%$ CI $)$ & $\beta(95 \%$ CI $)$ \\
\hline \multicolumn{5}{|l|}{ Age } \\
\hline$\leq 30$ years & 1.00 & 1.00 & 1.00 & 1.00 \\
\hline $31-35$ years & $0.02(-0.17,0.21)$ & $\begin{array}{c}0.10(-0.10, \\
0.29)\end{array}$ & $-0.33(-0.61,-0.05)$ & $\begin{array}{c}-0.02(-0.32, \\
0.29)\end{array}$ \\
\hline$\geq 36$ years & $0.21(-0.01,0.43)$ & $\begin{array}{c}0.24(0.01 \\
0.46)\end{array}$ & $-0.36(-0.69,-0.04)$ & $\begin{array}{c}0.29(-0.06 \\
0.63)\end{array}$ \\
\hline \multicolumn{5}{|l|}{ Ethnicity } \\
\hline Chinese & 1.00 & 1.00 & 1.00 & 1.00 \\
\hline Malay & $0.24(0.04,0.44)$ & $\begin{array}{c}0.27(0.06, \\
0.48)\end{array}$ & $0.02(-0.29,0.32)$ & $0.48(0.16,0.80)$ \\
\hline Indian & $0.31(-0.06,0.69)$ & $\begin{array}{c}0.41(0.02, \\
0.80)\end{array}$ & $0.02(-0.55,0.58)$ & $\begin{array}{c}0.37(-0.24 \\
0.97)\end{array}$ \\
\hline Others & $-0.02(-0.39,0.25)$ & $\begin{array}{c}-0.16(-0.44 \\
0.12)\end{array}$ & $-0.28(-0.68,0.12)$ & $\begin{array}{c}0.19(-0.24 \\
0.61)\end{array}$ \\
\hline \multicolumn{5}{|l|}{ Education } \\
\hline $\begin{array}{l}\text { Primary/ } \\
\text { secondary }\end{array}$ & 1.00 & 1.00 & 1.00 & 1.00 \\
\hline $\begin{array}{l}\text { Post- } \\
\text { secondary }\end{array}$ & $0.04(-0.26,0.34)$ & $\begin{array}{c}-0.08(-0.40, \\
0.24)\end{array}$ & $0.11(-0.35,0.56)$ & $\begin{array}{c}-0.14(-0.62 \\
0.34)\end{array}$ \\
\hline Tertiary & $0.23(-0.07,0.52)$ & $\begin{array}{c}-0.23(-0.53 \\
0.08)\end{array}$ & $-0.06(-0.50,0.38)$ & $\begin{array}{c}-0.12(-0.59 \\
0.35)\end{array}$ \\
\hline \multicolumn{5}{|l|}{ Frontline job } \\
\hline No & 1.00 & 1.00 & 1.00 & 1.00 \\
\hline Yes & $-0.12(-0.29,0.06)$ & $\begin{array}{c}-0.22(-0.40, \\
-0.04)\end{array}$ & $-0.03(-0.28,0.23)$ & $0.28(0.01,0.56)$ \\
\hline \multicolumn{5}{|l|}{$\begin{array}{l}\text { History of } \\
\text { miscarriage }\end{array}$} \\
\hline No & 1.00 & 1.00 & 1.00 & 1.00 \\
\hline Yes & $-0.12(-0.32,0.08)$ & $\begin{array}{c}-0.28(-0.49, \\
-0.07)\end{array}$ & $-0.11(-0.42,0.19)$ & $\begin{array}{c}-0.32(-0.64 \\
0.01)\end{array}$ \\
\hline \multicolumn{5}{|l|}{ Type of clinic } \\
\hline General & 1.00 & 1.00 & 1.00 & 1.00 \\
\hline High-risk & $0.08(-0.10,0.27)$ & $\begin{array}{c}0.20(0.01 \\
0.39)\end{array}$ & $-0.03(-0.30,0.25)$ & $\begin{array}{c}-0.02(-0.31 \\
0.27)\end{array}$ \\
\hline
\end{tabular}

Data were analysed using the multiple linear regression models. CI, confidence interval

\section{Supplementary Files}

This is a list of supplementary files associated with this preprint. Click to download.

- Appendix10nlineSurvey.docx 